\title{
Detección del área con desierto florido en el territorio del Mar de Dunas de Atacama, mediante percepción remota ${ }^{1}$
}

\author{
Consuelo Castro Avaria², Álvaro Montaña Soto ${ }^{3}$, Carlos Pattillo Barrientos ${ }^{4}$ \\ y Álvaro Zúñiga Donoso 5
}

\begin{abstract}
RESUMEN
El Mar de Dunas de Atacama, situado al noroeste de Copiapó $27^{\circ} \mathrm{S}$, cubre una superficie de 335 kilómetros cuadrados constituyendo un "erg" cuya morfología es muy compleja por la influencia topográfica de valles y cerros subyacentes. El espacio natural circundante corresponde a las terrazas marinas de Caldera y a planos inclinados cubiertos por mantos eólicos donde ocurre la floración del desierto. El territorio en conjunto es parte del geopatrimonio de Atacama, cuyo valor científico y natural se incrementa también por la vegetación de niebla existente. Utilizando imágenes satelitales y levantamientos de terreno, se determinó la distribución espacial del fenómeno del desierto florido y de la vegetación de niebla en el territorio próximo al Mar de Dunas. Los resultados junto a la cartografía generada, constituyen una base científica necesaria para las propuestas de ordenación territorial de dicho espacio.
\end{abstract}

Palabras clave: Mar de Dunas, desierto florido, tillandsias, imágenes satelitales, percepción remota.

\begin{abstract}
The Atacama Dune Sea is located northwest of Copiapó $\left(27^{\circ} \mathrm{S}\right)$ and covers an area of $335 \mathrm{~km}^{2}$, constituting an "erg" whose morphology is very complex due to the influence of underlying valley and hill topography. The natural space environment corresponds to Caldera's marine terraces and inclined planes covered by aeolian mantles where desert blooms occur. The entire territory is part of the Atacama's geo-heritage, whose natural and scientific value is increased by the existent fog vegetation. Using satellite imagery and field surveys, we determined the spatial distribution of the blooming desert phenomenon and fog vegetation present in the Dune Sea area. Our results, in conjunction with the cartography generated, constitute a useful and necessary scientific basis for land use planning in this invaluable territory.
\end{abstract}

Key words: Dune Sea, blooming desert, tillandsias, satellite images, remote sensing.

\footnotetext{
1 Agradecimientos a FONDECYT por el financiamiento del Proyecto $\mathrm{N}^{\circ} 1100400$ y a Francisco Chirino, Jorge Espinoza y Nancy Matus del Gobierno Regional de Atacama, por su dedicada colaboración y apoyo. Artículo recibido el 12 de abril de 2012 aceptado el 13 de junio de 2013 y corregido el 27 de septiembre de 2013.
}

2 Instituto de Geografía, Pontificia Universidad Católica de Chile (Chile). E-mail: consuelo@uc.cl

3 Centro de estudio y conservación del patrimonio natural, CECPAN (Chile). E-mail: agmontan@uc.cl

4 Centro de Percepción Remota (Chile). E-mail: carlos. pattillo@cpr.cl

5 Instituto de Geografía, Pontificia Universidad Católica de Chile (Chile). E-mail: azunigdo@uc.cl 
El medio natural en el área de Caldera y Copiapó, posee variados elementos geomorfológicos, geológicos y paleontológicos que constituyen un geopatrimonio (Murray, 2004: 6) de gran interés científico, educacional y cultural. Dichos lugares, acorde con los postulados de UNESCO (1999), corresponden a geositios destacados de la III Región de Atacama (Castro et al., 2007: 111). Así, la relevancia geopatrimonial del Mar de Dunas de Atacama ha sido señalada en varios artículos científicos que fundamentan su singularidad geomorfológica y sedimentológica, junto con la recomendación de propender a su preservación (Araya-Vergara, 2001: 63; Paskoff et al., 2003: 356; Castro et al., 2012:14).

La relevancia del espacio natural señalado, se acrecienta aún más por la existencia de ecosistemas desérticos originales de vegetación de niebla y por la germinación del desierto florido, cuya biogeografía y especies vegetales han sido expuestas en los trabajos de Cereceda et al., 2000: 38; Luebert et al., 2006: 73; Gutiérrez, 2008: 285; Squeo et al., 2008a: 29; Squeo et al., 2008b: 5; entre otros. En efecto, concurren en dicho territorio un conjunto de condiciones propicias para la germinación esporádica del desierto y la existencia de vegetación de niebla en lugares favorables, todo lo cual incrementa la importancia natural y científica de dicho espacio del desierto costero del norte de Chile.

Por sus atributos paisajísticos y naturales, el Servicio Nacional de Turismo ha delimitado y designado el área del Mar de Dunas como Zona de Interés Turístico (ZOIT; SERNATUR, 2007: 9). En efecto, las dunas y su entorno son el escenario y soporte de actividades turísticas y deportivas extremas como el Raid de Atacama desde 1985 y el Rally Dakar a partir del año 2009. La importancia económica del lugar también se debe a la explotación minera del subsuelo y de las arenas eólicas ricas en hierro. De este modo, concurren en dicho espacio el interés económico con la necesidad de preservar su naturalidad y calidad paisajística debido al interés científico que posee (Paskoff et al., 2003: 355; Araya-Vergara, 2001: 27; Castro et al., 2012: 123; Castro et al., 2013: 64).

De acuerdo a lo anterior, cabe preguntarse: ¿Cuáles son los sitios donde germina el desierto florido y la vegetación de niebla en el Mar de Dunas y terrenos circundantes? ¿Hay vegetación en las dunas activas? ¿Es adecuado el uso de imágenes satelitales para la detección de la vegetación en un medio arenoso de alta reflectancia? ¿Cómo el estudio espacial de la vegetación contribuye al ordenamiento territorial en el área de estudio?

Así, en este artículo se exponen los resultados de un estudio para determinar la distribución espacial del desierto florido y de la vegetación de niebla en el Mar de Dunas y el territorio aledaño que corresponde a las terrazas marinas de Caldera y los planos inclinados o glacis ver Figuras $\mathrm{N}^{0} 1$ y $\mathrm{N}^{\circ} 2$ ), con el fin de aportar los datos necesarios para un estudio integrado que sirva para entregar recomendaciones para la ordenación territorial del área. En efecto, el análisis de la distribución de la vegetación se efectuó dentro del contexto de una investigación más amplia llevada a cabo con el objetivo de fundamentar la originalidad y relevancia territorial del Mar de Dunas como elemento constituyente del geopatrimonio del desierto de Atacama (Castro, 2005: 114; Castro et al., 2012: 130; Castro et al., 2013: 64). Así, la cartografía del desierto florido y de la vegetación de niebla que se presentan en este artículo, son parte de los datos científicos requeridos para elaborar una propuesta de zonificación del área de emplazamiento del Mar de Dunas, según metodologías de análisis espacial multicriterio (Barredo, 1996: 54; Saaty, 2001: 124). En dicha zonificación, la presencia de vegetación singular es uno de los criterios esenciales de valoración para la determinación de unidades territoriales, el cual se integra con otros criterios relevantes como son la presencia de geositios en el área; su interés geomorfológico; y la existencia de áreas de protección, según se expone en Castro et al., 2013: 58.

Entonces, en este artículo se presentan los antecedentes geográficos del área de estudio; se expone la metodología para el análisis espacial del desierto florido y de la vegetación de niebla; se determinan los factores geográficos de dicha distribución junto al análisis de la cartografía generada y, finalmente, se concluye respecto del interés de la metodología empleada y las características de las áreas de floración del desierto y vegetación de niebla 
Figura $\mathrm{N}^{\circ} 1$

Mar de Dunas de Atacama y su entorno, Copiapó.
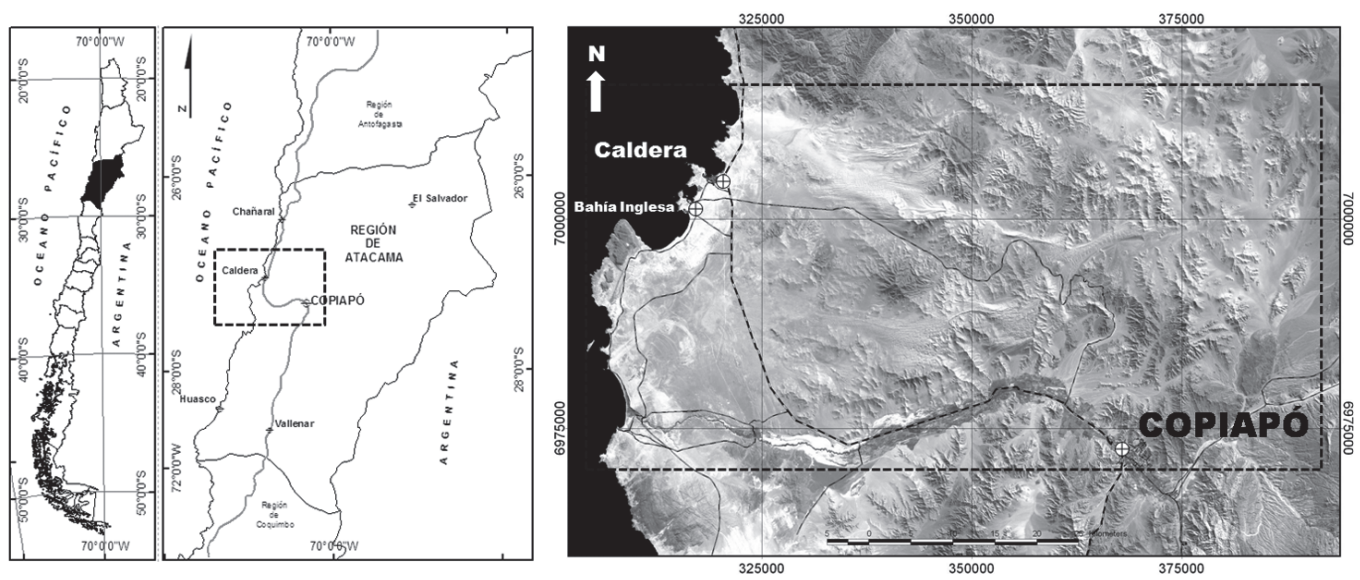

Fuente: Elaboración propia.

en el lugar de emplazamiento del Mar de Dunas de Atacama, Figura $N^{0} 1$.

Situado al noroeste de la ciudad de Copiapó, el Mar de Dunas de Atacama corresponde a un vasto conjunto de dunas desérticas continentales que conforman un erg (Fryberger et al., 1979: 140; Araya-Vergara, 2001: 31), el cual cubre una superficie de
335 kilómetros cuadrados (Castro et al., 2012:1). La morfología de las dunas está influenciada por la topografía de valles y cerros subyacentes, y se reconocen tipologías de formas dunarias compuestas y complejas (Livingstone et al., 2007: 250; Araya-Vergara, 2001: 62; Paskoff et al., 2003: 356; Castro et al., 2012: 131).

Figura $\mathrm{N}^{\circ} 2$

Unidades geomorfológicas de la zona costera de Caldera y Copiapó, Atacama.

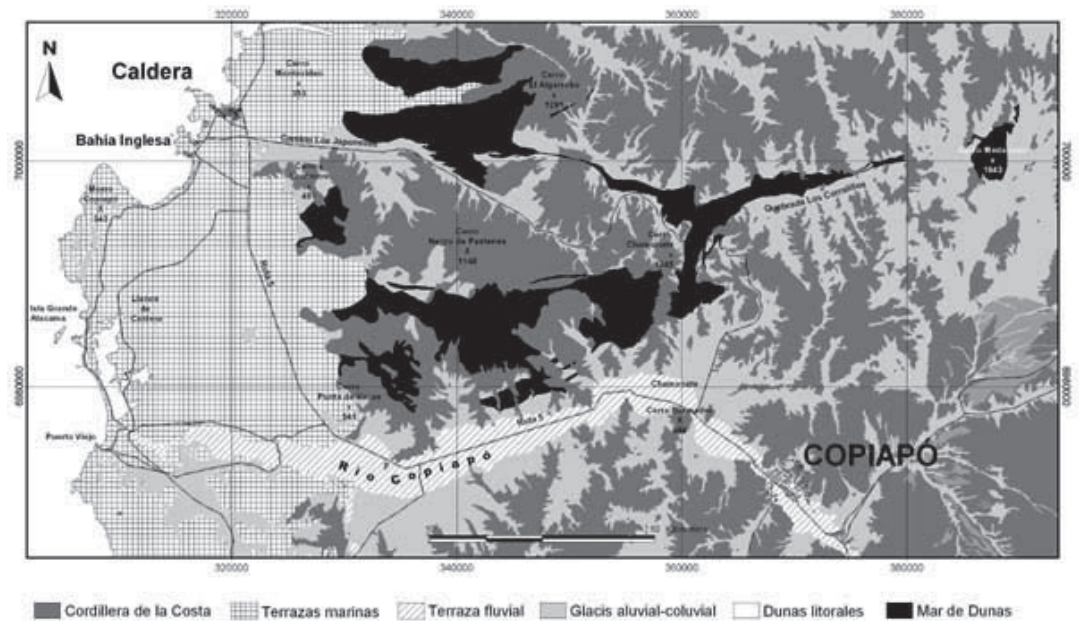

Fuente: Castro et al., 2012: 124. 
El cuerpo principal del erg de Atacama se compone de voluminosas dunas activas desprovistas de vegetación; sin embargo, en los márgenes que las delimitan y los terrenos próximos se reconocen diversos tipos de dunas entrabadas por algunas especies vegetales que se disponen dispersas. En efecto, los interfluvios que separan los distintos campos de dunas corresponden a planos inclinados de glacis aluvio-coluviales; laderas de cerros y terrazas marinas cubiertas por mantos de arenas eólicas de escaso espesor (Figura $\mathrm{N}^{\circ} 2$ ) (Castro et al., 2011: 53; Castro et al., 2012: 9).

El clima en el área es desértico nuboso de influencia oceánica, con una temperatura promedio de $15^{\circ}$ Celsius y una moderada variación térmica diaria y anual. Las Iluvias son muy escasas y ocurren en los meses de invierno, alcanzando un promedio anual de 32 $\mathrm{mm}$ en Caldera; las Iluvias ocasionales que provocan la floración del desierto ocurren en los años de eventos El Niño-Oscilación del Sur como se muestra en el Cuadro $N^{\circ} 1$. De acuerdo a Luebert et al. (2006: 284), los bioclimas que condicionan la vegetación natural en el sector costero de la Región de Atacama son el Mediterráneo Hiperdesértico (hasta los $28^{\circ}$ de latitud) y el Mediterráneo Desérticooceánico hasta $29^{\circ} 30^{\prime}$ Sur.

\section{Cuadro $\mathrm{N}^{\circ} 1$}

Lluvias asociadas a eventos El Niño, período 1970-1997 estación Copiapó-Chamonate $27^{\circ} 24^{\prime} \mathrm{S} / 70^{\circ} 24^{\prime} \mathrm{W}$

\begin{tabular}{|l|r|r|r|}
\hline Año & \multicolumn{1}{|c|}{ mm } & \multicolumn{1}{c|}{ Año } & \multicolumn{1}{c|}{ mm } \\
\hline 1970 & 3 & 1984 & 27,3 \\
\hline 1971 & 0 & 1985 & 3,5 \\
\hline 1972 & $\mathrm{~S} / \mathrm{i}$ & 1986 & 9,8 \\
\hline 1973 & 7,5 & 1987 & 60,6 \\
\hline 1974 & 3 & 1988 & 1,9 \\
\hline 1975 & 2,5 & 1989 & 16,5 \\
\hline 1976 & 3,1 & 1990 & $\mathrm{~S} / \mathrm{i}$ \\
\hline 1977 & 11,7 & 1991 & 59,2 \\
\hline 1978 & 0 & 1992 & 38,7 \\
\hline 1979 & $\mathrm{~s} / \mathrm{i}$ & 1993 & 0 \\
\hline 1980 & 29,3 & 1994 & 0 \\
\hline 1981 & 5 & 1995 & 0 \\
\hline 1982 & 0,5 & 1996 & 0 \\
\hline 1983 & 42,6 & 1997 & 138,6 \\
\hline
\end{tabular}

s/i: Sin información.

Fuente: Dirección Meteorológica de Chile, varios años.
Con respecto a las metodologías empleadas para el estudio del medio natural de los desiertos, el uso de las imágenes satelitales ha sido fundamental en las investigaciones geomorfológicas de los erg, porque permite una mejor comprensión de la estructura interna y disposición de estos complejos sistemas geomorfológicos. Los trabajos de Livingstone et al. (2007: 241) y también Kocurek et al. (2005: 95) coinciden en la utilidad de las imágenes de satélites para clasificar las dunas según tipologías geomorfológicas y, particularmente, en la determinación de los patrones internos de organización de los vastos mares de arena continentales.

En relación al estudio de la vegetación de los desiertos a partir de imágenes satelitales, Hesse (2012: 33) y Borthagaray et al. (2010: 18), respectivamente, emplean imágenes de alta resolución para el análisis y mapeo de la distribución espacial de la vegetación de niebla en la costa peruana. En Chile, Castro et al. (2005: 31), a partir de imágenes Landsat y medición de radiometría de campo en el sector costero de la bahía de Tongoy, determinaron las curvas espectrales características de playas, dunas y distintas especies vegetales, lo cual facilita el reconocimiento, delimitación y clasificación tanto de las formas como de la vegetación. Por otra parte, para los estudios vegetacionales sistemáticos, Tucker et al. (1986: 1342) proponen el Índice de Vegetación de Diferencias Normalizadas (NVDI), de utilidad para el análisis de la variabilidad espacio-temporal de la vegetación (Kawabata et al., 2001: 1380; Lee et al., 2002: 2507).

\section{Metodología de detección del desierto florido a partir de imágenes satelitales procesadas}

En la investigación desarrollada se utilizaron imágenes satelitales y reconocimiento de terreno como instrumentos metodológicos esenciales para determinar la distribución del desierto florido y de la vegetación de niebla en el territorio circundante al Mar de Dunas de Atacama.

Una importante dificultad para el análisis con imágenes satelitales, es la confusión de la señal espectral de la vegetación con aquella de las arenas de las dunas y de las 
coberturas eólicas presentes en gran parte del territorio en estudio. En efecto, la vegetación de niebla corresponde a especies bromeliáceas cuya distribución es dispersa y sus hojas son duras y de baja reflectancia; por ello, este tipo de vegetación es perceptible en imágenes de satélite de resolución media o baja. Por su parte, las especies vegetales del desierto florido forman una cobertura vegetal más densa con especies de hojas blandas que se caracterizan por tener una alta reflectancia en el espectro visible y muy alta en el infrarrojo cercano. Considerando lo anterior, para detectar el cambio de densidad en la cubierta vegetal se utilizaron imágenes Landsat 5-7 y Aster, que corresponden a sensores de resolución media; también se utilizaron imágenes tomadas en años secos y en años húmedos.

Basándose en las diferencias de valores de reflectancia entre la banda del Rojo, que tiene mínima reflectancia por absorción de esas longitudes de onda por la clorofila, y la banda del Infrarrojo cercano, se pueden separar los píxeles que tienen vegetación de los que no tienen. Para ello se utilizó el Índice Vegetacional de Diferencias Normalizadas o NDVI cuya expresión es la siguiente:

$$
\mathrm{NDVI}=(\mathrm{IRC}-\text { Rojo }) /(\mathrm{IRC}+\text { Rojo })
$$

Donde IRC es la cuenta digital en la banda del Infrarrojo Cercano (de 0 a 255); y Rojo es la cuenta digital en el Rojo (de 0 a 255), el gráfico de la Figura $\mathrm{N}^{\circ} 3$ representa los valores extremos.

Figura $\mathrm{N}^{\circ} 3$

Índice Vegetacional de Diferencias Normalizadas (NDVI)

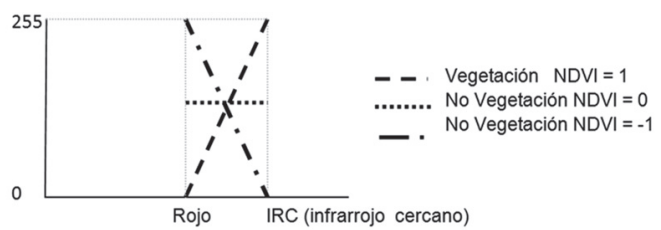

Fuente: Elaboración propia.

Teóricamente, valores de NDVI mayores a 0 corresponden a vegetación; sin embargo en la realidad hay elementos cuya curva espectral también tiene un valor de Rojo menor al infrarrojo, y si ambos son altos su valor tiende a 0 por efecto de la normalización. Por ejemplo, una diferencia de 10 entre el Infrarrojo Cercano IRC y el Rojo, con valores altos, e.g. suma de 490 da un NDVI $=0.02$ y con valores bajos, e.g. suma de 30 , la misma diferencia de 10 da un NDVI $=0.3$ y lo más probable es que ninguno de estos píxeles sea vegetación.

De lo anterior se deduce que para aplicar este índice se debe previamente analizar el área de estudio y observar los valores mínimos y máximos que se producen en ambas bandas espectrales para los diferentes elementos que cubren la zona, por ejemplo, especies vegetales y densidad de cobertura; o bien, tipos de arena y efectos de la humedad. Dicho análisis permite determinar los rangos de las cuentas digitales que realmente corresponden a vegetación y, por ende, cuáles rangos del NDVI son válidos para separar la vegetación de otros elementos. Entonces, la fórmula se aplica con valores límites en ambas bandas.

Se analizó la imagen Landsat del 24 de julio de 2010, con presencia del fenómeno del desierto florido, mediante perfiles espectrales para las bandas del Rojo e IRC y se modificó la fórmula de la siguiente manera:

$\mathrm{Al}$ numerador (A) de la fórmula se le puso la condición de que la diferencia, que realmente representa presencia de vegetación, es mayor a 15, es decir A = Si (IRC - Rojo) > 15 entonces vale la expresión (IRC-Rojo), si no el valor es 0 . Para el denominador (B), la condición controla que la suma de ambos valores no sea mayor o igual a 170 ya que suma sobre este valor normalmente es arena activa, nubes, nieve o ruido. Entonces $\mathrm{B}=\mathrm{Si}(\mathrm{IRC}+$ Rojo) $<170$ entonces (IRC + Rojo) si no 0. Se verifica finalmente que el denominador (B) sea $>0$ en el momento de calcular el NDVI = $A / B$ y en el caso de que B sea 0 , entonces el NDVI es igual a 0 .

Con el fin de llevar estos valores a un rango de 8 bits, se modificó la fórmula de la siguiente manera: NDVI $=((\mathrm{A} / \mathrm{B})+1) * 127$. En nuestro caso, el mínimo valor válido para vegetación dio 139 y el máximo 201 (0.1 a 0.58 en valores originales). El efecto importante de este proceso es que se eliminaron automáticamente todas las confusiones de 
elementos que no eran vegetación, pero que daban también valores entre 0.1 y 1 .

En la Figura $\mathrm{N}^{\circ} 4$ del área de estudio se muestra el resultado del NDVI en su versión original (A), separado en cuatro niveles de grises, donde el negro corresponde a las áreas sin vegetación y el blanco a las zonas más densas y/o fotosintéticamente más activas. Al aplicar las restricciones indicadas, el resultado cambia notablemente como se observa en (B).

Al analizar el resultado, comparándolo con la imagen original en falso color con- vencional o composición infrarrojo color (vegetación en color Rojo), se aprecia que el resultado con la fórmula modificada se ajusta mucho más a la interpretación visual que realizaría un intérprete (Figura $N^{\circ} 5$ ).

Con el fin de extraer de la imagen resultante la vegetación permanente como cultivos, praderas y matorrales presentes en el vaIle del río Copiapó, la cual es detectable por el sensor, se procesó la imagen del 24 de julio de 2007, que corresponde a un año seco, sin la presencia del desierto florido como se observa en la Figura $N^{\circ} 5$.

Figura $\mathrm{N}^{\circ} 4$

Comparación de NDVI original y modificado con la imagen original, en el área de emplazamiento del Mar de Dunas de Atacama.
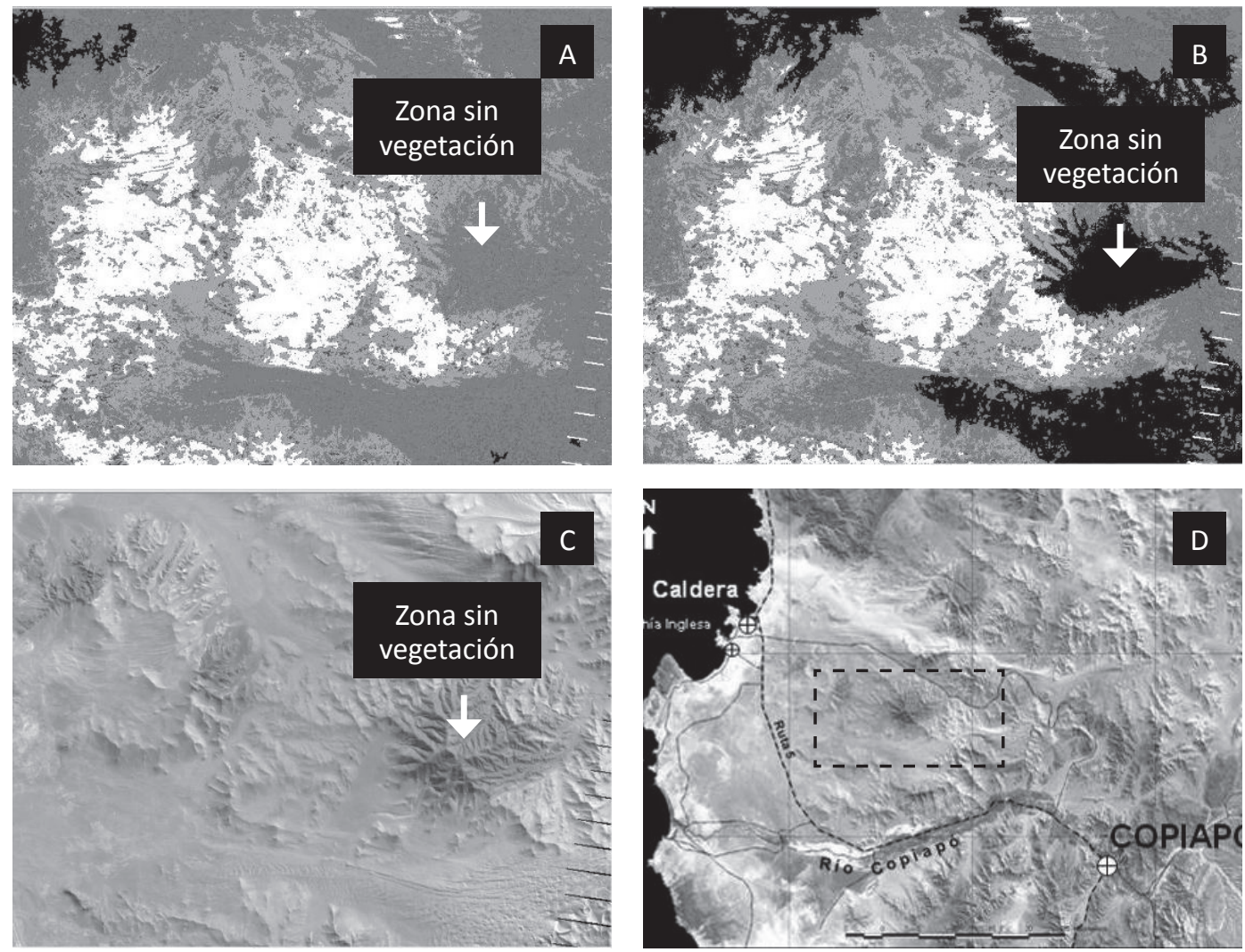

A) NDVI sin modificar; B) NDVI modificado según límites espectrales de la vegetación; C) Imagen Landsat original; D) Mapa de localización área de estudio.

Fuente: Elaboración propia. 
Figura $\mathrm{N}^{\circ} 5$

Imagen satelital del territorio del Mar de Dunas con y sin desierto florido

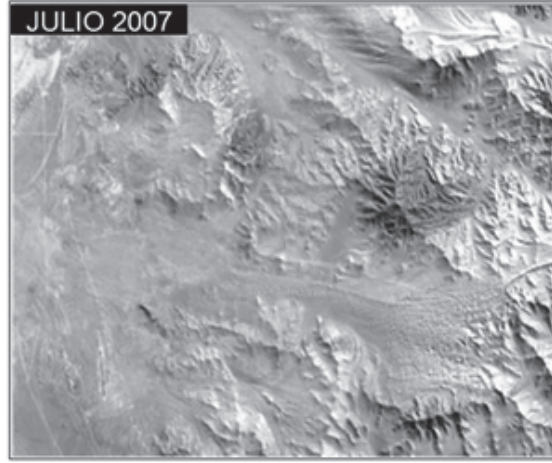

Ausencia de desierto florido.

Fuente: Elaboración propia.

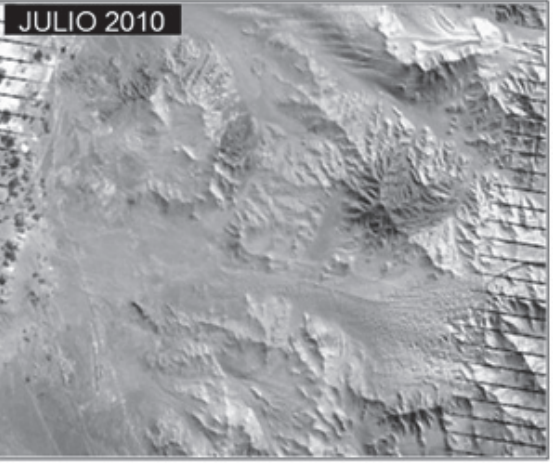

Presencia de desierto florido.
Siguiendo el procedimiento indicado, se realizó el cálculo del índice vegetacional modificado, con el cual se detectó la vegetación en las áreas de cultivo y en quebradas. Al hacer la diferencia entre ambos resultados, se generan las áreas donde realmente se produce el fenómeno del desierto florido. Con el fin de integrar esta información con el resto de las coberturas tratadas en un sistema de información geográfico, se convierte el producto del procesamiento de la imagen de raster a vector (polígonos) y se aplican filtros para eliminar áreas pequeñas o menores a 5 píxeles. El resultado de esta operación se sintetiza en la Figura $\mathrm{N}^{\circ} 8$ que muestra la distribución del desierto florido en el área de estudio, la cual se analiza más adelante.

\section{Metodología de identificación de la vegetación de niebla}

Se efectuaron campañas de terreno donde se constató que la especie dominante es Tillandsia landbeckii, la cual se distribuye en grupos de plantas que se disponen alineadas; así, los campos de Tillandsia sp. se identificaron a partir del reconocimiento de los patrones de textura de tillandsias vivas y muertas, mediante el análisis visual de imágenes Digital Globe disponibles en Google Earth y validación en terreno (Figura $N^{\circ}$ 6). Se emplearon imágenes satelitales de los años 2002, 2004 y 2011, con las que se creó un fotomosaico digital. El análisis visual abarcó un cuadrante de $40 \times 40 \mathrm{~km}$, equivalentes a $1.600 \mathrm{~km}^{2}$, cuyas coordenadas UTM son 7.015 .00 norte a 6.975 .00 norte y 327.400 este a 367.400 este.

Una vez verificados los patrones texturales de los campos de tillandsias en terreno y en imágenes satelitales (Figura $\mathrm{N}^{\circ} 6$ ), se realizó una exhaustiva búsqueda a escala 1:5.000 de paños de tillandsiales en Google Earth y en el fotomosaico digital; así, se digitalizaron en Arcgis los contornos de los paños de tillandsias, definiendo con ellos una cobertura de polígonos. En base a esta última cobertura se realizó una serie de análisis espaciales para determinar la presencia, ausencia y frecuencia de tillandsias, según un Modelo de Elevación Digital SRTM, Shuttle Radar Topographic Mission, que se elaboró a partir de datos de radar con resolución espacial de 90 metros y cobertura global. Con dicha base topográfica se determinaron las orientaciones de laderas, altitudes y pendiente, además de las coberturas de geomorfología y formaciones superficiales generadas para la investigación (Castro et al., 2013: 59).

\section{Singularidad de la vegetación en el territorio colindante al Mar de Dunas de Atacama}

El territorio en estudio, se sitúa al norte del Sitio Prioritario denominado Desierto Florido de Los Llanos, que abarca una su- 
Figura $\mathrm{N}^{\circ} 6$

Mantos eólicos y Mar de Dunas de Atacama: patrones texturales de tillandsias muertas y vivas.
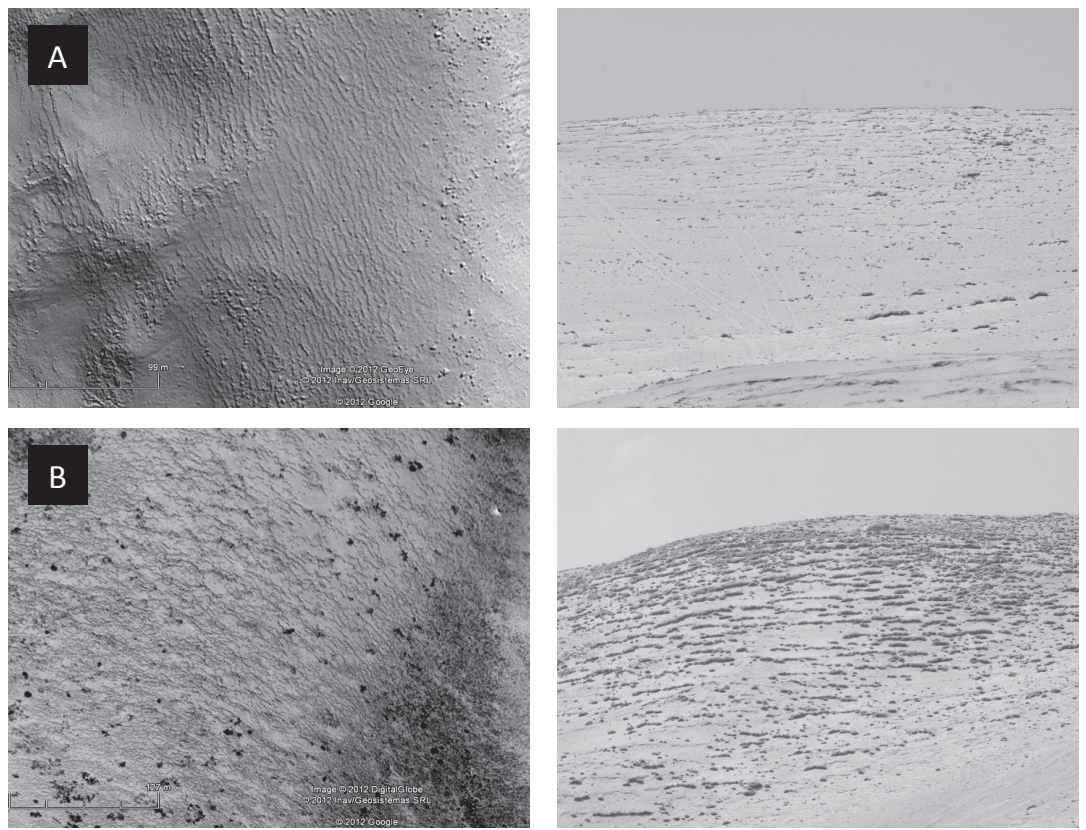

A) Imagen satelital y fotografia de terreno del patrón de Tillandsias muertas. B) Imagen satelital y fotografia de terreno del patrón de Tillandsias vivas. Fuente: Elaboración propia en base a imágenes Google Earth.

perficie de $1.746 \mathrm{~km}^{2}$ (Squeo et al., 2008a: 37), y se localiza 29 kilómetros al sur de Copiapó. De acuerdo a los autores citados, aquí se encuentra la mayor diversidad florística y vegetacional del evento esporádico del desierto florido, con 241 especies nativas, de las cuales dos de ellas presentan problemas de conservación. También, los autores citados señalan que, fuera de los límites del sitio prioritario, la presencia de flora y vegetación del desierto florido es escasa e irregular en su distribución, localizándose dispersa en Ilanos arenosos interiores y costeros; como ocurre con el área colindante con el Mar de Dunas que se analiza en el presente artículo.

La floración del desierto es provocada por lluvias esporádicas que permiten la germinación de plantas geófitas y de semillas en estado de latencia (Gutiérrez, J., 2008: 285), que se encuentran en los mantos de arena que cubren la superficie de las terrazas marinas y planos inclinados (Figura $\mathrm{N}^{\circ} 2$ ); dicho fenómeno también ha sido descrito en sus aspectos biogeográficos y florísticos por
Luebert et al., 2006: 102; Squeo et al., 2008a: 185; Squeo et al., 2008b: 29. Es preciso señalar que estudios como el de Cereceda et al. (2000:40) demuestran que no todos los años lluviosos provocan la misma densidad de cobertura del desierto florido, como lo explica dicha autora comparando los eventos de 1991 en que se produjo mayor germinación y floración que en el evento de 1977, donde la distribución de la floración fue muy extensa ocupando hasta más al norte de las terrazas marinas de Caldera, Cuadro $N^{\circ} 1$.

Junto a la vegetación esporádica del desierto florido, se desarrollan en el área campos dispersos de comunidades de especies que mayoritariamente pertenecen al género Tillandsia sp. En efecto, el farellón costero característico de la costa del norte chileno, no se encuentra en la sección sur del litoral de Atacama, lo que facilita el paso de la niebla costera, por corredores, hacia los Ilanos interiores de Caldera y las laderas de las serranías en Copiapó. Este es un factor esencial para la existencia de paños de tillandsias en 
los terrenos próximos al Mar de Dunas en donde las plantas retienen parte de las arenas transportadas por el viento, formando dunas entrabadas sobre la superficie de terrazas marinas y planos inclinados aledaños al gran Mar de Dunas (Figuras $N^{\circ} 7$ y $N^{\circ} 8$ ). Dichos tillandsiales se encuentran mayoritariamente en el piso vegetacional del ecosistema de matorral desértico interior de Cuerno de Cabra, Skytanthus acutus, y de Cachiyuyo, Atriplex desertícola, según la clasificación de Luebert et al. (2006: 84).

Por su parte, los estudios tanto de Cereceda et al. (1999: 3) como de Pinto et al. (2006: 543) atribuyen la presencia de tillandsias al efecto de la camanchaca en sus respectivas áreas de estudio en Iquique y Arica, en el norte de Chile. También Hesse (2012:33), para explicar los extensos tillandsiales del desierto costero del sur de Perú, señala que su presencia depende de la humedad de la niebla en aquellas áreas donde esta ocurre con suficiente frecuencia, duración e intensidad, como se observa en el Cuadro $\mathrm{N}^{\circ} 3$ donde se comparan, según diferentes autores, los factores de localización de tillandsias en lugares como Arica, Iquique y Copiapó en Chile; y Pisco en Perú.

\section{Caracterización de la distribución espacial del desierto florido próximo al Mar de Dunas de Atacama}

Al analizar las coberturas de vegetación obtenidas a partir de las imágenes satelitales procesadas, según se explicó precedentemente en la metodología, se observa en la Figura $N^{\circ} 8$ la distribución del desierto florido circundante al Mar de Dunas. Dicho fenómeno se presenta en los Ilanos cubiertos con mantos de arenas sobre las terrazas marinas más elevadas que se localizan al interior de Caldera y Bahía Inglesa. Se extiende 35 kilómetros hacia el sur hasta el valle del río Copiapó, cubriendo una superficie total de 487 $\mathrm{km}^{2}$, con gran continuidad espacial.

Asimismo, de acuerdo a la Figura $N^{\circ} 7$, se distinguen dos sectores con desarrollo del desierto florido, los cuales se disponen se- parados por un campo de dunas semiactivo. El primer sector se sitúa entre los 300 y 700 metros sobre el nivel del mar, y se extiende al norte del camino de Los Japoneses cubriendo una superficie de $152 \mathrm{~km}^{2}$. El segundo sector se localiza al sur de dicha vía y su extensión es de $273 \mathrm{~km}^{2}$, Ilegando hasta las cercanías de la Ruta 5 y el valle del río Copiapó. Si bien este último sector se caracteriza por una floración muy continua, se destaca en su parte central la presencia de un extenso campo de dunas semiactivas que corresponden a una sección sur del Mar de Dunas. Ambos sectores de floración del desierto presentan hacia sus márgenes un cambio en la continuidad espacial, conformando un conjunto de pequeñas unidades interconectadas o individuales; esta condición se relaciona con la existencia de dunas activas, o bien de substratos rocosos y relieves de los cerros de la cordillera de la Costa en donde el fenómeno del desierto florido se circunscribe a los fondos de pequeños valles. Las unidades pequeñas de superficie inferior a $1 \mathrm{~km}^{2}$ alcanzan en conjunto aproximadamente $61 \mathrm{~km}^{2}$ equivalentes al $13 \%$ del total del área donde se produce el fenómeno del desierto florido en el territorio del Mar de Dunas. Estos lugares se sitúan junto a los márgenes de las dos unidades de desierto florido en el área, ya descritos.

Asimismo, otros lugares de escasa superficie de floración del desierto, ocurren en los Llanos de Caldera; en los mantos de arenas de las terrazas marinas por debajo de los 150 metros sobre el nivel del mar, y también inmediatamente al norte de la desembocadura del río Copiapó.

Entonces, del análisis de la distribución según rangos altitudinales, se deduce que por debajo de los 100 metros sobre el nivel del mar, la presencia de vegetación del desierto florido es muy escasa y se restringe a sectores aislados de las terrazas marinas más bajas con cubiertas superficiales pedregosas.

Entre 100 y 300 metros sobre el nivel del mar, la extensión de la floración es casi continua, en los sustratos que conforman los mantos de arenas eólicas en la superficie de las terrazas marinas más altas, y también en algunos corredores del tránsito del viento hacia el interior de las serranías. 
Por sobre los 300 y hasta los 700 metros sobre el nivel del mar se presenta la mayor densidad de cobertura del desierto florido, el cual se extiende en forma continua sobre cubiertas arenosas y depósitos aluviales; también en los piedemontes y quebradas de las serranías costeras.

A mayor altura el desierto florido ocurre en paños dispersos de escasa superficie y se circunscribe a los flancos de las quebradas y serranías, hasta una distancia aproximada de 40 kilómetros de la costa, lo que también permite inferir el máximo avance de la camanchaca proveniente de la orilla litoral. En cotas próximas a los 1.000 metros sobre el nivel del mar, bajo las cumbres de los cerros Negro de Pastene y cerro El Algarrobo, el fenómeno del desierto florido es prácticamente inexistente debido a los afloramientos roco- sos, fuertes pendientes y ausencia de substratos arenosos.

En la síntesis del Cuadro $N^{\circ} 2$ se muestra que el fenómeno del desierto florido ocurre de preferencia en los substratos arenosos de poco espesor existentes en sitios de topografía subhorizontal correspondiente a la estructura de las terrazas marinas y llanos, y también en los planos inclinados situados en la base de la cordillera de la Costa. El desierto florido también ocurre en las dunas estabilizadas y/o dunas semiestabilizadas, y dicho fenómeno no se desarrolla en el cuerpo de las dunas activas. Lo anterior se establece a partir de límites claramente reconocibles señalados en la cartografía de la Figura $N^{\circ} 7$ que muestra las áreas donde se presenta el desierto florido, aledañas a los contornos que delimitan las dunas activas correspondientes a los diferentes sectores del Mar de Dunas.

Figura $\mathrm{N}^{\circ} 7$

Distribución del desierto florido (NDVI Modificado) en terrazas marinas y planos inclinados en el territorio del Mar de Dunas de Atacama

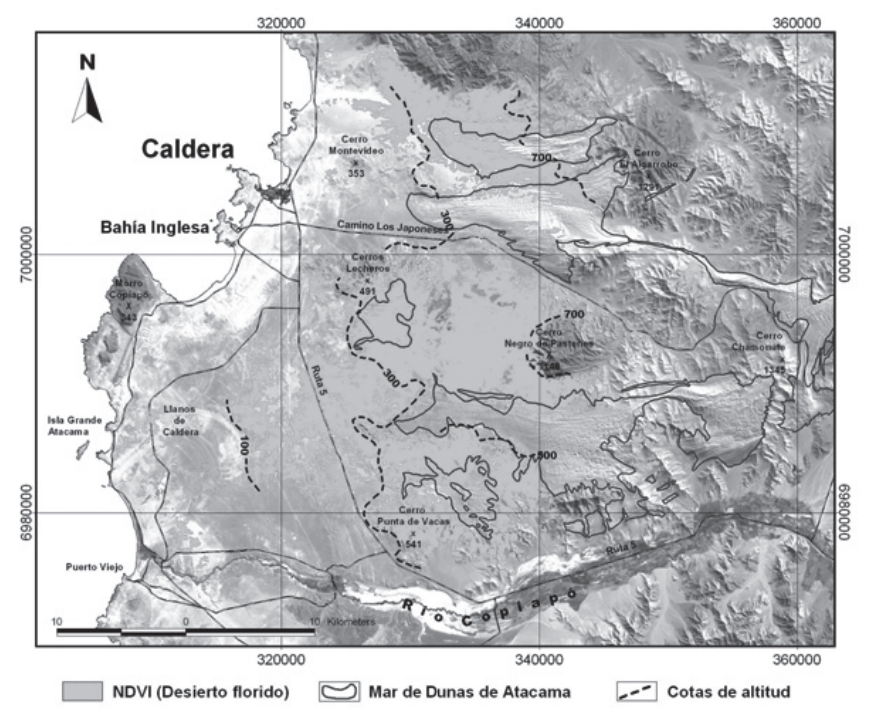

Fuente: Elaboración propia, procesamiento imagen satelital del año 2010. 
Síntesis de la distribución del desierto florido en torno al Mar de Dunas de Atacama

\begin{tabular}{|c|c|}
\hline Localización & $\begin{array}{l}\text { El desierto florido se extiende desde Duna Ramadas, situada al norte de } \\
\text { Caldera, hasta la desembocadura del río Copiapó. Hacia el este de la Ruta } \\
5 \text { se desarrolla con continuidad espacial hasta } 20 \text { kilómetros hacia el in- } \\
\text { terior. La extensión del desierto florido es esporádica en la franja entre la } \\
\text { Ruta } 5 \text { y la costa, según se observa en la Figura } N^{\circ} 8 \text {. }\end{array}$ \\
\hline $\begin{array}{l}\text { Superficie total } \\
\text { áreas de floración }\end{array}$ & $487 \mathrm{~km}^{2}$ \\
\hline Altitud & $\begin{array}{l}\text { Su distribución ocurre entre los } 100 \text { y } 700 \text { metros, con mayor continuidad } \\
\text { espacial entre los } 300 \text { y } 700 \text { metros sobre el nivel del mar. }\end{array}$ \\
\hline Origen & $\begin{array}{l}\text { Relacionado con la ocurrencia de Iluvias ocasionales intensas, durante } \\
\text { eventos El Niño-Oscilación del Sur, según se observa en Cuadro } N^{\circ} 1 .\end{array}$ \\
\hline $\begin{array}{l}\text { Geomorfología } \\
\text { y formaciones } \\
\text { superficiales }\end{array}$ & $\begin{array}{l}\text { La floración ocurre de preferencia sobre mantos de arenas eólicas de poco } \\
\text { espesor y en menor medida en los substratos pedregosos de los llanos que } \\
\text { conforman las terrazas marinas sedimentarias, localizadas entre los } 100 \text { y } \\
300 \text { metros sobre el nivel del mar. } \\
\text { También ocurre desierto florido en los sustratos de los depósitos aluviales } \\
\text { y coluviales de los fondos de valles y en los planos inclinados, respectiva- } \\
\text { mente, situados entre los } 300 \text { y } 700 \text { metros sobre el nivel del mar, hasta la } \\
\text { base de los cerros de la cordillera de la Costa. } \\
\text { En forma ocasional, el desierto florido puede ocurrir en algunos valles inte- } \\
\text { riores altos situados a una distancia no mayor de } 40 \text { kilómetros de la costa } \\
\text { y a una altura no superior a los } 900 \text { metros sobre el nivel del mar. } \\
\text { El desierto florido también germina en los sustratos de dunas semiestabi- } \\
\text { lizadas y/o estabilizadas, y también en los corredores interdunarios por } \\
\text { donde transita el viento. Así, ocurre desierto florido en los márgenes de los } \\
\text { campos de dunas activas y no al interior de ellos. }\end{array}$ \\
\hline $\begin{array}{l}\text { Usos humanos y } \\
\text { actividades en el } \\
\text { Mar de Dunas }\end{array}$ & $\begin{array}{l}\text {-Tránsito de vehículos todo terreno. } \\
\text {-Rutas del Raid Atacama, a través de caminos consolidados o huellas para- } \\
\text { lelas de decenas de metros de ancho. } \\
\text { - Rutas Rally Dakar, a través de caminos consolidados o huellas. } \\
\text {-Restos de basuras domésticas y vertedero de Caldera. } \\
\text { - Áreas de ejercicios militares. } \\
\text { - Instalaciones de faenas de minería extractiva }\end{array}$ \\
\hline
\end{tabular}

\section{La vegetación de niebla y los factores de su localización en el territorio del Mar de Dunas de Atacama}

Utilizando la metodología expuesta precedentemente, se identificaron 211 paños de vegetación de niebla en el territorio aledaño al Mar de Dunas, los que en conjunto constituyen $54 \mathrm{~km}^{2}$ de comunidades vegetales monoespecíficas de Tillandsia Landbeckii. Según se observa en la Figura $N^{\circ}$ 8, los campos de tillandsias localizados más al oeste se encuentran a 18 kilómetros del borde costero y los más distantes se sitúan a no más de 50 kilómetros de este.

En el entorno inmediato de las grandes dunas se localizan dos extensos paños de tillandsias; el primero se sitúa en el sector norte, unos 20 kilómetros al interior de la localidad 
de Rodillo, y tiene una superficie de 9,6 km² ocupando relieves residuales de baja altitud cercanos a las serranías de la cordillera de la Costa. El paño de tillandsias sur es más extendido, con $44,7 \mathrm{~km}^{2}$ de superficie y se localiza 30 kilómetros al interior de Caldera, próximo al camino de Los Japoneses, con algunos paños aislados hacia el este y el sur. Como se observa en la Figura $N^{\circ}$ 8, los tillandsiales están separados por las vastas extensiones de dunas continentales activas y por serranías.

Los tillandsiales se distribuyen entre los 328 y 1.138 metros de altitud, donde el rango comprendido entre los 600 y 1.000 metros agrupa al $70 \%$ de los paños de tillandsias reconocidos, según se muestra en la Figura $N^{\circ} 10$. Dicho segmento de altitud con mayor abundancia de vegetación de niebla es coincidente con lo descrito por Cereceda et al.
(1999:7) en la Región de Tarapacá, y Hesse (2012: 39) en Perú. Lo señalado indica que la localización de tillandsiales bajo los 1.000 metros de altitud se relaciona con la frecuencia espacio-temporal de la gruesa nube estratocúmulo generadora de la camanchaca, como lo precisa Cereceda et al. (1999: 9). Así, el límite altitudinal de la presencia de tiIlandsias en el área colindante al Mar de Dunas, está determinado por el umbral mínimo de altitud que permite interceptar la camanchaca proveniente de la costa; y el umbral máximo está condicionado por las mayores alturas de las serranías costeras con cerros de hasta 1.200 metros (Figura $N^{\circ}$ 9).

La abundancia de tillandsia también depende de la orientación de las laderas que interceptan la humedad de la camanchaca transportada por los vientos predominantes

Figura $\mathrm{N}^{\circ} 8$

Distribución de campos de tillandsias en el entorno del Mar de Dunas de Atacama

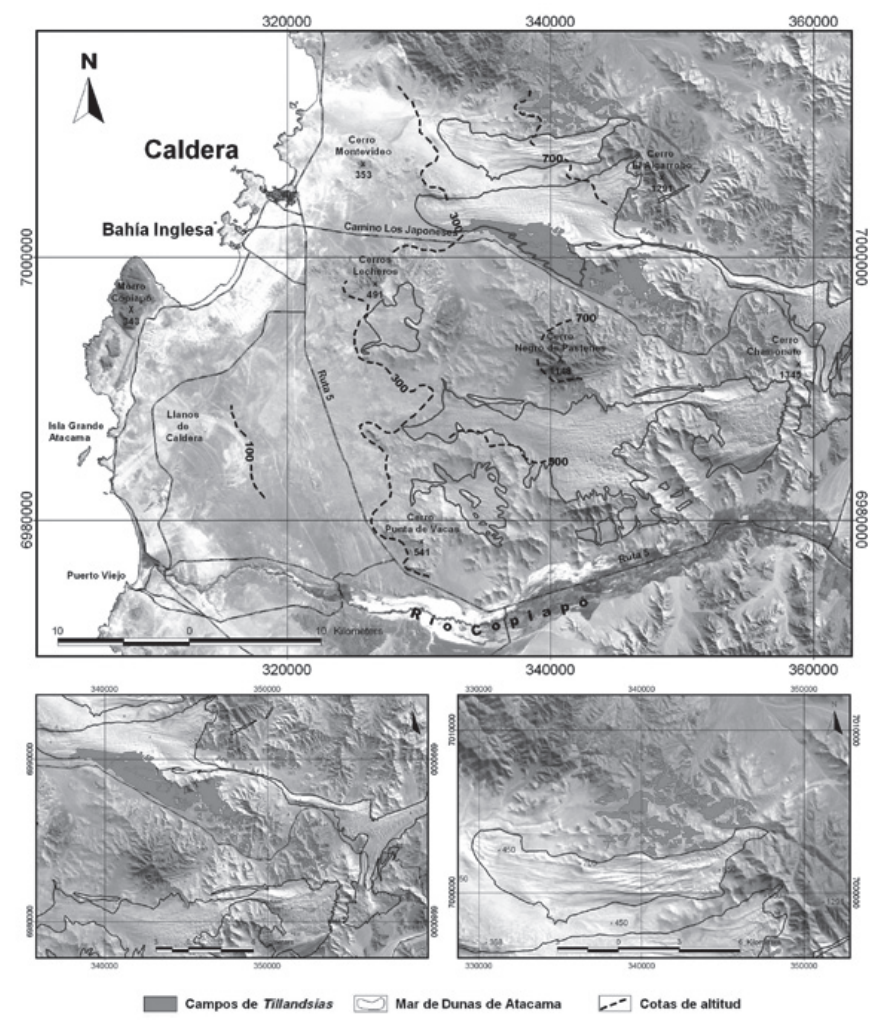

Fuente: Elaboración propia. 

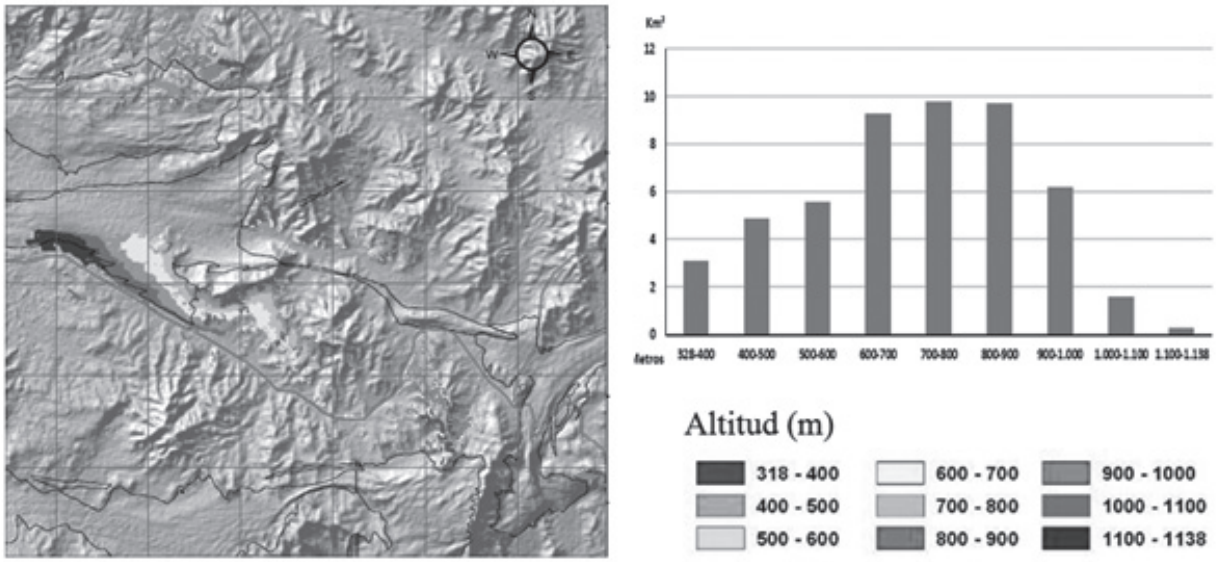

Fuente: Elaboración propia a partir de Modelo Digital de Elevación.

del oeste y suroeste, según los registros del Servicio Meteorológico de la Armada de Chile. En el área de estudio se observa que $77,3 \%$ de la superficie de tillandsiales se localiza en laderas expuestas a vientos provenientes del oeste, suroeste y sur, como se observa en la Figura $N^{\circ} 10$. Así, las laderas de orientación suroeste, expuestas a la dirección de los vientos dominantes, alcanzan el mayor porcentaje de extensión de tillandsias. En consecuencia, el control topográfico es también un factor que condiciona la distribución espacial de esta especie vegetal, como también lo establece Hesse (2012:36) para los tillandsiales situados entre Pisco y Acarí, en Perú.

De acuerdo a los resultados de otros autores en sus investigaciones sobre tillandsias, se puede determinar que la distribución latitudinal de tillandsiales en el desierto costero de América del Sur abarca desde los $13^{\circ} \mathrm{S}$ en Perú, según Hesse (2012: 34). En el Norte Grande de Chile, los tillandsiales situados en las serranías costeras de Iquique $\left(20^{\circ} \mathrm{S}\right)$, son caracterizados por Cereceda (1999: 8-9). Así mismo, los campos de tillandsias situados en las quebradas entre Arica $\left(18^{\circ} \mathrm{S}\right)$ y el río Loa $\left(21^{\circ} \mathrm{S}\right)$, son estudiados por Pinto et al. (2006: 546-547). Por su parte, el presente estudio establece que dichas comunidades vegetales del desierto costero nuboso, también se encuentran a los $26^{\circ} \mathrm{S}$ en su distribución más austral, según se observa en el Cuadro $\mathrm{N}^{\circ} 3$.
Figura $\mathrm{N}^{\circ} 10$

Territorio del Mar de Dunas de Atacama, orientación de laderas

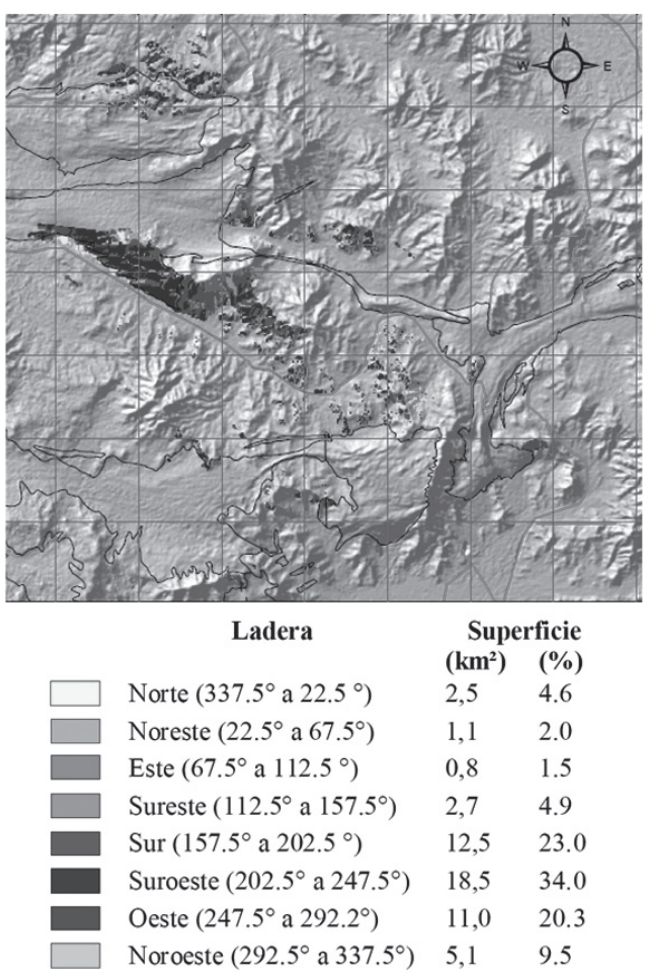

Fuente: Elaboración propia a partir de modelo digital de elevaciones SRTM. 
Cuadro $\mathrm{N}^{\circ} 3$

Síntesis comparativa de los factores de localización de Tyllandsia Landbeckii en el desierto costero del norte de Chile y sur del Perú

\begin{tabular}{|c|c|c|c|c|}
\hline $\begin{array}{l}\text { Factores de } \\
\text { distribución }\end{array}$ & $\begin{array}{l}\text { Cereceda et al., } \\
1999\end{array}$ & Pinto et al., 2006 & Hesse, 2012 & $\begin{array}{l}\text { Castro et al., } \\
2012\end{array}$ \\
\hline Lugar y latitud & $\begin{array}{l}\text { Cerro Guatalaya, } \\
\text { Iquique } 20^{\circ} 17^{\prime} \mathrm{S}\end{array}$ & $\begin{array}{c}\text { Arica-río Loa } \\
18^{\circ} 20^{\prime} \mathrm{S}-21^{\circ} 25^{\prime} \mathrm{S}\end{array}$ & $\begin{array}{l}\text { Pisco-Acarí, Perú } \\
13^{\circ} 40^{\prime} \mathrm{S}-15^{\circ} 37^{\prime} \mathrm{S}\end{array}$ & $\begin{array}{l}\text { Caldera-Copiapó } \\
26^{\circ} 58^{\prime} \mathrm{S}-27^{\circ} 20^{\prime} \mathrm{S}\end{array}$ \\
\hline Altitud (m) & 500-1.000 & $900-1.200$ & $467-1.129$ & $328-1.138$ \\
\hline $\begin{array}{l}\text { Superficie } \\
\text { con tillandsia } \\
\text { landbeckii }\end{array}$ & - & $68,6 \mathrm{~km}^{2}$ & $605,8 \mathrm{~km}^{2}$ & $54,3 \mathrm{~km}^{2}$ \\
\hline $\begin{array}{l}\text { Superficie área } \\
\text { de estudio }\end{array}$ & - & - & $15.777 \mathrm{~km}^{2}$ & $1.600 \mathrm{~km}^{2}$ \\
\hline $\begin{array}{l}\text { Orientación } \\
\text { predominante de } \\
\text { laderas }\end{array}$ & Oeste & Suroeste y oeste & Oeste y suroeste & Suroeste y oeste \\
\hline $\begin{array}{l}\text { Distancia } \\
\text { máxima a línea } \\
\text { de costa }\end{array}$ & $16 \mathrm{~km}$ & $45 \mathrm{~km}$ & $65 \mathrm{~km}$ & $50 \mathrm{~km}$ \\
\hline $\begin{array}{l}\text { Geomorfología y } \\
\text { Topografía }\end{array}$ & Laderas cerros & $\begin{array}{c}\text { Laderas de } \\
\text { quebradas } \\
\text { profundas; } \\
\text { Llanos arenosos }\end{array}$ & Lomas & $\begin{array}{l}\text { Llanos y planos } \\
\text { inclinados }\end{array}$ \\
\hline Substrato & Arenas eólicas & Arenosos & - & Mantos arenosos \\
\hline
\end{tabular}

Fuente: Elaboración propia.

\section{La distribución de la vegetación singular y la zonificación del territorio del Mar de Dunas}

Las coberturas de los campos de tillandsias y del desierto florido obtenidas, se relacionaron en un sistema de información geográfico, con el fin de integrar los resultados de localización de la vegetación singular existente en el área de estudio. Un primer aspecto a destacar, según se observa en la Figura $N^{\circ} 11$, es que dicha vegetación se emplaza en diferentes espacios próximos al Mar de Dunas y que hay escasa superposición espacial de ambas, siendo únicamente los fondos de valles y quebradas los lugares de emplazamiento común para las tillandsias y el desierto florido.

Por debajo de los 700 metros sobre el nivel del mar, según se observa en la Figura $N^{\circ}$
11, alternan los espacios ocupados por dunas activas con amplias depresiones interdunarias por donde circula el viento; los substratos corresponden a mantos de arena estabilizados por la vegetación permanente del ecosistema de matorral desértico interior citado precedentemente, y en donde ocurre el desierto florido cuando las condiciones de humedad son propicias.

Los paños de tillandsias, en tanto, se ubican en el sector norte del camino Los Japoneses que atraviesa las serranías de la cordillera de la Costa donde se emplaza el Mar de Dunas. Aquí, las cubiertas eólicas y las dunas de diversas morfologías (Castro et al., 2012: 9) cubren parcialmente los cerros, y los tillandsiales, que estabilizan parcialmente las dunas, deben su localización a la orientación favorable de las laderas para interceptar la niebla costera y a la topografía con pendientes de hasta $15^{\circ}$. 


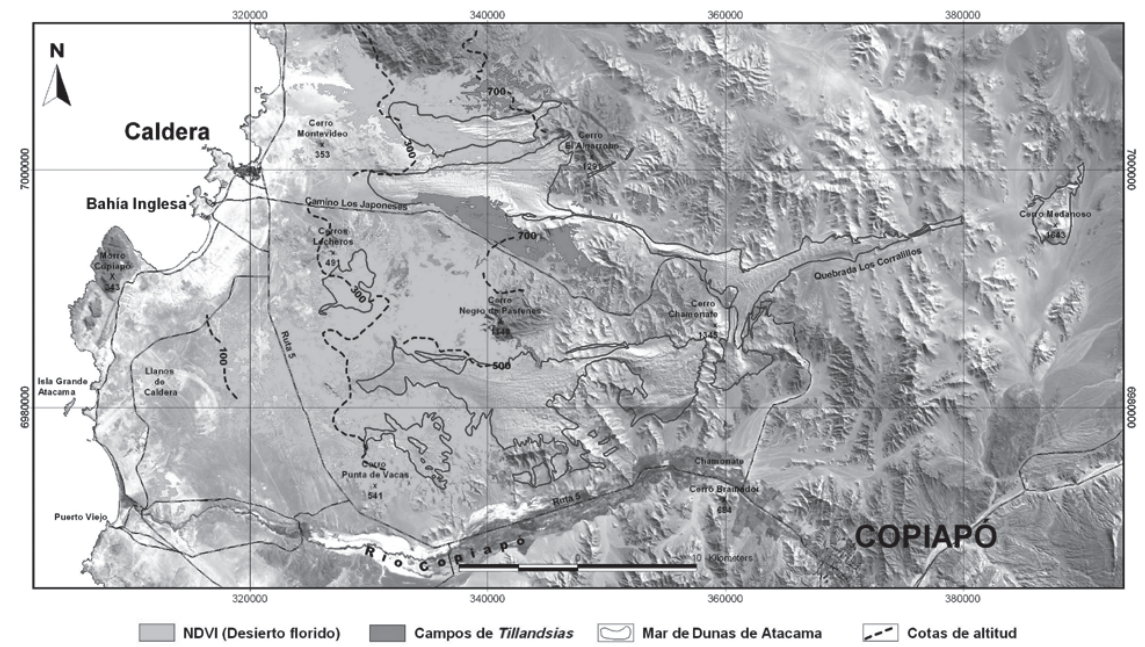

Fuente: Elaboración propia.

Por sobre los 700 metros sobre el nivel del mar, las dunas se agrupan en familias de formas de vastas extensiones de arenas tanto semiestabilizadas como activas (Castro et al., 2012: 9-10); aquí no hay germinación de flores y los campos de tillandsias se restringen a paños dispersos en los flancos de las quebradas.

La cartografía de la vegetación singular del área de estudio, que se muestra en la Figura $N^{0} 11$, constituye uno de los antecedente fundamentales como criterio de valoración del territorio para elaborar una propuesta de zonificación del Mar de Dunas y su entorno, en unidades de gestión para la asignación de usos compatibles, según lo establecido en Castro et al., 2013: 67, a partir de los resultados del estudio de la distribución espacial de la vegetación aquí expuestos.

\section{El geopatrimonio del territorio Mar de Dunas de Atacama en la ordenación territorial}

En el sector del desierto de Atacama en estudio, su reconocido valor geopatrimonial (Castro et al., 2011: 52; Castro et al., 2012:
123) y natural presentado en el marco del presente artículo, suscita una demanda turística significativa en la zona costera siendo reconocida por el Servicio Nacional de Turismo (SERNATUR, 2011) al determinar 32 atractivos turísticos de diferente jerarquía entre el granito orbicular por el norte y la playa Puerto Viejo por el sur. Dichos atractivos se agrupan en el área turística prioritaria "Caldera-Bahía Inglesa" (SERNATUR, 2011: 18). De igual forma, varios de dichos atractivos turísticos se ubican en terrenos al interior de Bienes Nacionales protegidos, como figura de protección de predios fiscales (Ministerio de Bienes Nacionales), el cual procura la conservación ambiental y el manejo sostenible de recursos en predios fiscales.

Si bien las áreas turísticas prioritarias no son un instrumento de planificación territorial, ellas permiten espacializar la gestión de SERNATUR, por lo que el área de desierto florido identificada podría ser catalogada como atractivo de jerarquía internacional, de acuerdo a la jerarquía de atractivos turísticos de SERNATUR (2011), titulado "Homologación y Actualización de Bases Georreferenciadas de Atractivos Turísticos para el SIG Sernatur"; tal es el caso del área de desierto florido de 
Llanos de Caldera, situada al sur del río Copiapó; como también, ser incluida dentro del área turística prioritaria "Caldera-Bahía Inglesa" (Figura No 12).

El valor ecológico del área en estudio, es reconocido por el Ministerio de Medio Ambiente mediante la declaración del Sitios Prioritarios para la Conservación de la Biodiversidad "Desierto florido" (Ministerio del Medio Ambiente, 2012), el cual incluye prácticamente la totalidad de los tillandsiales identificados; sin embargo, en dicho espacio no se consideran los sectores de desierto florido identificados en la presente investigación, como por ejemplo en torno al aeropuerto de Copiapó (Figura № 12), en el sector de Monte Amargo, al sur del área de estudio, área que, por lo demás, es identificada por Squeo et al., 2008b; y Squeo et al., 2008c, como futuro sitio prioritario de conservación de la biodiversidad dada la presencia de especies nativas de flora vulnerables y en peligro.

De acuerdo a lo expuesto en el área del Mar de Dunas de Atacama y su entorno, se reconoce la existencia de una superposición espacial de figuras de conservación y desarrollo turístico. Dichas áreas son susceptibles de ser redelimitadas al tomar en consideración los nuevos antecedentes aportados por este artículo; con ello, se procura favorecer el ámbito espacial de la toma de decisiones en materias de planificación y gestión del territorio; y en particular, la conservación del patrimonio natural que puede sustentar actividades recreativas, científicas, educativas y de conservación.

Figura $\mathrm{N}^{\circ} 12$

Figuras de gestión y ordenación territorial, Caldera-Copiapó, 27ºS, Atacama

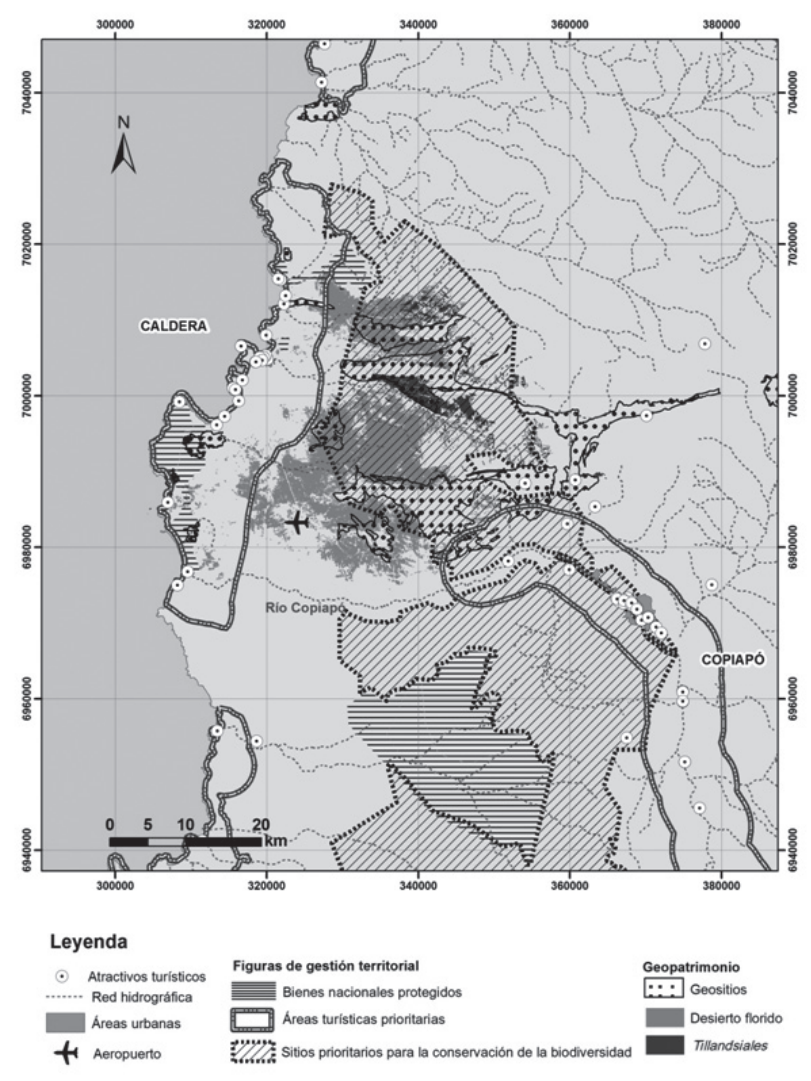

Fuente: Elaboración propia. 


\section{Conclusiones}

La distribución espacial del desierto florido y de la vegetación de niebla en el área de estudio está fuertemente condicionada por las estructuras geomorfológicas. En efecto, en las llanuras con sustratos arenosos correspondientes a las terrazas marinas y los piedemontes por debajo de los 700 metros sobre el nivel del mar, germina el desierto florido. La vegetación de niebla, en cambio, se distribuye en los fondos de valles y laderas de orientación sur y oeste de las serranías de la cordillera de la Costa entre los 700 y 1.100 sobre el nivel del mar. El grado de estabilización de los substratos arenosos es otro factor condicionante ya que, en aquellos substratos de escasa movilidad o estabilizados, germina el desierto florido y la vegetación de niebla, no así sobre las acumulaciones eólicas activas del Mar de Dunas de Atacama. Asimismo, no se observa desarrollo de vegetación en los sectores desprovistos de mantos eólicos.

El procesamiento de imágenes satelitales a partir del cálculo del Índice Vegetacional de Diferencias Normalizadas (NVDI) constituye un método eficiente para la determinación de la distribución de tipos de vegetación en ambientes desérticos con substratos arenosos. Al mismo tiempo, es un complemento a los métodos tradicionales de reconocimiento de patrones texturales de la vegetación obtenidos a través de fotografías aéreas, imágenes y observaciones de terreno. En cuanto al establecimiento de la delimitación de los contornos de los mares de arenas, son concordantes los resultados obtenidos utilizando los métodos de observación convencionales, con aquellos obtenidos a partir de percepción remota espacial, todo lo cual ratifica la eficiencia y utilidad de esta última.

La definición de la distribución espacial de la vegetación de niebla y del desierto florido permite establecer áreas y delimitaciones naturales muy claras y acotadas en el territorio en estudio; dichos sitios coinciden con la localización de otros elementos del geopatrimonio en torno al Mar de Dunas de Atacama, y también, con algunas figuras de protección como los Sitios Prioritarios de Atacama o las áreas propuestas por los autores como Geositios en trabajos anteriores. En conjunto, todos estos elementos potencian el valor de dicho territo- rio y a la vez, determinan su fragilidad natural para acoger diversas actividades y usos humanos. En consecuencia, los resultados obtenidos contribuyen a los procesos de ordenamiento y gestión del territorio de la Tercera Región, los cuales deben difundirse y darse a conocer en los distintos servicios regionales para ser considerados en los estudios de elaboración de los planes regionales de desarrollo.

Finalmente, se continuará con la divulgación científica de los resultados obtenidos en las instancias científicas, administrativas, políticas y educacionales que corresponda, con el fin de promover, ante UNESCO, la solicitud de la nominación de la categoría de Geoparque para dicho territorio del sur del desierto de Atacama.

\section{Referencias Bibliográficas}

ARAYA-VERGARA, J. Los Ergs del desierto marginal de Atacama, Chile. Revista Investigaciones Geográficas Chile, 2001, № 35, p. 27-66.

BARREDO, J.I. Sistemas de Información Geográfica y Evaluación multicriterio. Madrid: Editorial Ra-Ma, 1996.

BORTHAGARAY, A.I.; FUENTES, M.E. \& MARQUET, P.A. Vegetation pattern formation in a fog-dependent ecosystem. Journal of Theoretical Biology, 2010, № 265, p. 18-26.

CASTRO, C. Geositios de valor patrimonial en Isla Grande de Atacama. En: GOBIERNO DE CHILE; GEF MARINO y PNUD. Áreas marinas y costeras protegidas de múltiples usos. Santiago de Chile: Ocho Libros Ediciones, 2007, p. 110-115.

CASTRO, C.; PATTILLO, C. y ZÚÑIGA, A. Mar de Dunas de Atacama, Copiapó: geopatrimonio y desarrollo territorial. En: PRIMER SIMPOSIO SOBRE GEOPARQUES. Actas. Melipeuco: Actas del primer simposio sobre geoparques, 2011, p. 52-55.

CASTRO, C.; PATTILLO, C. y ZÚÑIGA, A. Geomorfología y geopatrimonio del Mar de Dunas de Atacama, Copiapó $\left(27^{\circ} \mathrm{S}\right)$ Chile. Revista de Geografía Norte Grande, 2012, № 53, p. 123-136. 
CASTRO, C.; PATTILLO, C.; RIVERA, J. y ZÚÑIGA, A. Valoración territorial del geopatrimonio de la zona costera del sur del Desierto de Atacama, Chile $\left(27^{\circ} \mathrm{S}\right)$. Investigaciones Geográficas, 2013, 45, p. 51-72.

CASTRO, C.; PATTILLO, C. y ZÚÑIGA, A. Radiometría de campo en zonas costeras: el sistema geomorfológico de la bahía de Tongoy $\left(30^{\circ} 15^{\prime} \mathrm{S}\right)$, Chile. Terra Australis, 2005, $\mathrm{N}^{\circ} 50$, p. $17-31$.

CERECEDA, P.; LARRAÍN, H.; OSSES, P.; LAZARO. P.; GARCÍA J.L. Y HERNÁNDEZ, V. El factor clima en la floración del desierto en los años "El Niño" 1991 y 1997. Revista de Geografía Norte Grande, 2000, № 27, p. 37-52.

CERECEDA, P.; LARRAÍN, H.; LÁZARO, P.; OSSES, P.; SCHEMENAUER, R.S. y FUENTES, L. Campos de tillandsias y niebla en el desierto de Tarapacá. Revista de Geografía Norte Grande, 1999, № 26, p. 3-13.

GUTIÉRREZ, J. El Desierto Florido en la Región de Atacama. En: SQUEO, F.A.; ARANCIO, G. y GUTIÉRREZ, J.R. Libro Rojo de la Flora Nativa y de los Sitios Prioritarios para su Conservación: Región de Atacama. La Serena: Ediciones Universidad de La Serena, 2008, p. 285-291.

HESSE, R. Spatial distribution of and topographic controls on Tillandsia fog vegetation in coastal southern Peru: Remote sensing and modeling. Journal of Arid Environments, 2012, No 78, p. 33-40.

KAWABATA, A.; ICHII, K. \& YAMAGU$\mathrm{CHI}, \mathrm{Y}$. Global monitoring of interanual changes in vegetation activities using NDVI and its relationships to temperature and precipitation. Journal of Remote Sensing, 2001, Vol. 22, № 7, p. 1377-1382.

KOCUREK, G.; RYAN, C. \& EWING, R.C. Aeolian dune field self-organization, implications for the formation of simple versus complex dune-field patterns. Geomorphology, 2005, No 72, p. 94-105.

LIVINGSTONE, I.; GILES, F.; WIGGS, C. \& WEAVER, M. Geomorphology of desert sand dunes: A review of recen progress. Earth-Science Reviews, 2007, № 80, p. 239-257.

LEE, R.; YU, F.; PRICE, K.; ELLIS, J. \& SHI, P. Evaluating vegetation phonological patterns in Inner Mongolia using NDVI time-series analysis. Journal of Remote Sensing, 2002, Vol. 23, No 12, p. 2505-2512.

LUEBERT, F. y PLISCOFF, P. Sinopsis Bioclimática y Vegetacional de Chile. Santiago de Chile: Editorial Universitaria, 2006.

MINISTERIO DE MEDIO AMBIENTE. Infraestructura de datos espaciales. Servicios de mapas del Ministerio del Medio Ambiente. Chile: Sinia, 2012.

MURRAY, G. Geodiversity. London, England: Ed. Wiley, 2004.

PASKOFF, R.; CUITIÑO, L. y MANRÍQUEZ, H. Origen de las arenas dunares de la región de Copiapó, Desierto de Atacama, Chile. Revista Geológica de Chile, 2003, Vol. $30, N^{\circ} 2$, p. 355-361.

PINTO, R.; BARRÍA, I. \& MARQUET, P.A. Geographical distribution of Tillandsia lomas in the Atacama Desert, northern Chile. Journal of Arid Environment, 2006, № 65, p. 543-552.

SAATY, T.L. \& GONZÁLEZ, L. Models, Methods, Concepts \& Applications of the Analytic Hierarchy Process. Boston: Kluwer Academic, 2001.

SERVICIO METEOROLÓGICO DE LA ARMADA DE CHILE. Anuarios Meteorológicos Capitanía de Puerto de Caldera. Santiago de Chile: Directemar, 2005; 2006; 2007; 2008; 2009 y 2010.

SQUEO, F.A.; ARANCIO, G.; LETELIER, L.; LÓPEZ, D. y ESTÉVEZ, R.A. Antecedentes de los sitios prioritarios para la Conservación de la Flora Nativa Amenazada de la Región de Atacama. En: SQUEO, F.A.; ARANCIO, G. y GUTIÉRREZ, J.R. Libro Rojo de la Flora Nativa y de los Sitios Prioritarios para su Conservación: Región de Atacama. La Serena: Ediciones Universidad de La Serena, 2008a, p. 185-200. 
SQUEO, F.A.; ARANCIO, G.; LETELIER, L.; ARROLLO, M.; LEÓN LOBOS, P. y RENTERÍA-ARRIETA, L. Flora Amenazada de la Región de Atacama y Estrategias para su Conservación. En: SQUEO, F.A.; ARANCIO, G. y GUTIÉRREZ, J.R. Libro Rojo de la Flora Nativa y de los Sitios Prioritarios para su Conservación: Región de Atacama. La Serena: Ediciones Universidad de La Serena, 2008b, p. 29-44.

SQUEO, F.A.; LETELIER, L.; ESTÉVEZ, R.A.; CAVIERES, L.; MIHOC, M.; LÓPEZ, D.; y ARANCIO, G. Definición de los Sitios prioritarios para la conservación de la flora nativa de la región de Atacama. En: SQUEO, F.A.; ARANCIO, G. y GUTIÉRREZ, J.R. Libro Rojo de la Flora Nativa y de los Sitios Prioritarios para su Conservación: Región de Atacama. La Serena: Ediciones Universidad de La Serena, 2008c, p. 152-153.
TUCKER, C.J. \& SELLERS, P.J. Satellite remote sensing of primary production. Journal of Remote Sensing, 1986, Vol. 7, № 11, p. 1395-1416.

UNITED NATIONS EDUCATIONAL, SCIENTIFIC AND CULTURAL ORGANIZATION (UNESCO). Global geoparks network. Guidelines and Criteria for national geoparks seeking UNESCO's assistance to join the Global Geoparks Networks. Paris: UNESCO World Heritage Centre, 2008.

SERVICIO NACIONAL DE TURISMO (SERNATUR). Zonas y Centros de Interés Turístico Nacional. Antecedentes básicos para una Estrategia de Ordenamiento Territorial. Santiago de Chile, Sernatur, 2007.

SERVICIO NACIONAL DE TURISMO (SERNATUR). Áreas turísticas prioritarias de Chile. Santiago de Chile: Sernatur,2011. 
